\title{
The search conference as a method in planning community health promotion actions
}

\author{
Eva Magnus, ${ }^{1}$ Margunn Skjei Knudtsen,, ${ }^{2}$ Guri Wist, ${ }^{2}$ Daniel Weiss, ${ }^{1}$ Monica Lillefjell ${ }^{1}$ \\ ${ }^{1}$ Faculty of Health and Social Science, Department of Health Science, Norwegian University of \\ Science and Technology, Trondheim; ${ }^{2}$ Nord-Trondelag County Council, Nord-Trondelag, Norway
}

\section{Significance for public health}

This article describe and discuss how the Search conference can be used as a method when working with knowledge based health promotion actions in local communities. The article describe the sequences of the conference and shows how this have been adapted when planning and prioritizing health promotion actions in three Norwegian municipalities. The significance of the article is that it shows how central elements in the planning of health promotion actions, as participation and involvements as well as evidence was a fundamental thinking in how the conference were accomplished. The article continue discussing how the method function as both a top-down and a bottom-up strategy, and in what way working evidence based can be in conflict with a bottom-up strategy. The experiences described can be used as guidance planning knowledge based health promotion actions in communities.

\section{Abstract}

Aims: The aim of this article is to describe and discuss how the search conference can be used as a method for planning health promotion actions in local communities.

Design and methods: The article draws on experiences with using the method for an innovative project in health promotion in three Norwegian municipalities. The method is described both in general and how it was specifically adopted for the project.

Results and conclusions: The search conference as a method was used to develop evidence-based health promotion action plans. With its use of both bottom-up and top-down approaches, this method is a relevant strategy for involving a community in the planning stages of health promotion actions in line with political expectations of participation, ownership, and evidence-based initiatives.

\section{Introduction}

Norway has a history of emphasising a structural approach aimed at reducing health inequalities and promoting public health. ${ }^{1,2}$ According to the Public Health Act in Norway, local municipalities are requested to promote public health, well-being, and good social and environmental conditions. ${ }^{1}$ They are also encouraged to integrate public health issues into the local democracy with the aim of promoting health and welfare. ${ }^{2}$ The government emphasises the importance of social capital, social support, and participation in public health work-in fact, participation is seen as one of the key principles in public health work. ${ }^{2}$

Health promotion work presupposes the existence of intersectoral actions as described in the Sundsvall Statement of 1992. ${ }^{3}$ This statement underlines the importance of intersectoral actions for health within the setting of everyday life, and where environmental, organi- sational, and personal factors interact to affect health. To promote intersectoral action, World Health Organisation has initiated the Health in All Policies (HiAP) approach. ${ }^{4}$ HiAP is built on the rationale that health is determined by multiple factors that lie outside the direct control of the health care sector, such as education, income, and the conditions where people live, work, and play. This means that decisions made in sectors other than health care can either positively or negatively affect the determinants of health. Moreover, HiAP is an approach to policy making in which decision-makers in all sectors routinely consider health outcomes, including benefits, harms, and health-related costs. ${ }^{4}$

To meet these expectations, decisions in health promotion must be built on strong evidence. ${ }^{5-7}$ An increased focus on evidence-based health promotion means that local communities should actively adopt evidence-based strategies in selecting and implementing health actions. This includes employing the best available scientific evidence, using data and information systematically, applying program-planning frameworks, engaging the community in decision-making, conducting sound evaluations, and disseminating the resulting knowledge. ${ }^{5}$ Evidence-based strategies also involve the interplay of principles and values, ideology and evidence in decision-making. ${ }^{6}$ To accomplish evidence-based health promotion actions or programs, different types of approaches are necessary, such as leadership, community assessment, and participatory approaches. ${ }^{5,7}$ Raphael ${ }^{6}$ argues that since health promotion is about enabling people to improve their health, evidence relevant to health promotion should bear directly on activities that support enablement and empowerment.

Participation promotes a sense of belonging, engagement, and ownership within local communities, ${ }^{2}$ and a participatory approach is one of several elements of value found in the decision-making process for evidence-based health promotion. Participation has to do with the possible ways of receiving information or being involved in decision-making processes and/or self-determination. Arnstein ${ }^{8}$ described citizen participation as a ladder with eight rungs, ranging from non-participation at the bottom, described in the first two rungs as manipulation and therapy, up to citizen control at the top. In between are the rungs of informing, consultation, placation, partnership, and delegated power. Arnstein's ${ }^{8}$ personal commitment was a redistribution of power to the have-nots by empowering the poor and powerless. She also emphasised the idea of participation as a way of strengthening one's feelings of responsibility and ownership towards the environment.

Fosse ${ }^{9}$ discusses the importance of involving citizens, with a focus on process perspective in implementing health promotion actions at the municipal level. Fosse ${ }^{9}$ found that projects, aimed at integration and collaboration with local government administration, were more successfully implemented than were projects aimed at empowering local communities. This is not in line with a bottom-up perspective, in which initiatives are initiated by the citizens. Fosse ${ }^{9}$ argues that it is not a question of either/or but should be a combination of the two perspectives. This is underlined by Mittelmark and colleagues, ${ }^{10}$ who show how the complexity of health promotion actions requires the use 
of both bottom-up and top-down initiatives. They emphasise robust democracy, open debates, participation, and advocacy at all societal levels when working with health promotion.

A similar conclusion is found in Bloch and colleagues, ${ }^{11}$ which describes the supersetting approach in health promotion actions. This is an ecological approach, which builds on resources in the community, the strengths of social interaction, and local ownership in change processes. These interventions are knowledge-based and emphasise participation, empowerment, and context-sensitivity. Even if a bottomup, grassroots initiative with minor outside dominance is the ideal in this approach, the use of both top-down and bottom-up pathways is seen to be the most realistic way to develop a sustainable impact in community health promotion. ${ }^{11}$

To meet political expectations of evidence-based health promotion, as well as fulfil the need for belonging, engagement, and ownership, local communities need to decide which methods to use when developing and implementing health promotion actions. Several dialog methods such as consensus conferences, ${ }^{12}$ the nominal group technique, ${ }^{12-}$ ${ }^{14}$ consultative conferences, ${ }^{15}$ the future workshop, ${ }^{16}$ future search conferences $^{12}$ and search conferences ${ }^{17-20}$ have been used. Each of these methods focuses, in different ways, on the planning process, the involvement of participants, the dialogue process, and implementation.

In consensus conferences, ${ }^{12}$ representation of the entire citizen group is emphasised when choosing who to invite for participation, ending with 12 to 25 participants. These persons are given written evidence before they meet. After meeting, they decide which expert witnesses to call into the process, and continue with preparatory weekends before finally meeting for deliberations over the course of two to four days, with the end result of a report with recommendations for implementation. Similar to other methods, this type of conference is highly structured and designed to involve non-experts.

The nominal group technique, used in health promotion action planning, ${ }^{12-14}$ is described as a technique to assist participants in the process of pooling their knowledge and judgments to arrive at accepted decisions. The method consists of four stages: working on getting ideas, recording them in the group, discussing them, and eventually voting on the most important idea.

The consultative conference method is structured and uses the experience and knowledge of community workers to identify the strengths and limitations of various systems and methods. ${ }^{15}$ The conference itself consists of two sessions. The first session presents people's experiences in working on the topic of the conference in different ways. The second step facilitates group discussions by answering the questions: What works well? How can we do better? And what should we be doing? ${ }^{15}$ Ideas are gathered from the groups and then voted on to determine the most valued ideas.

Involving citizen groups in decision-making processes is also a central feature of the future workshop method. ${ }^{16}$ By using different techniques, the participants work through three main phases. First they investigate the problem critically by drawing on their previous experiences. Second, they work out a vision of a utopia of future possibilities in the fantasy phase. Third, in the implementation phase they evaluate and decide which ideas to realise.

The future search conference is a large-group planning meeting using face-to-face dialogue to develop plans, including the identification of action steps. ${ }^{12,21}$ This conference can include 60 to 80 participants, working for 16 hours across the space of three days both in groups and in plenary sessions, and invites experts to provide professional input. Participants tell stories about their past, present, and desired future, and discover common ground before they plan new actions. Problems and conflicts are treated as information, not action items, and they encourage participants to engage in self-management and take responsibility for actions before, during, and after the conference. $^{21}$
The search conference ${ }^{17-20}$ also represents a dialoguing conference. Initially developed in the 1960 s, this method is considered a practical tool for strategic planning. Its methodology involves participation aimed at increasing responsibility for the local community based on the following core principles: open systems thinking (an approach that takes a holistic look at components within a larger social environment), getting the right system in the room, puzzle solving and direct perception (rather than expert-driven problem solving), a democratic structure, meeting conditions for effective communication, and searching for common ground by rationalising conflicts. ${ }^{19}$

Although all of the above-mentioned dialogue conferences are highly structured, the search conference method differs from the others by placing a particular emphasis on community belonging, engagement, and ownership, as well as ensuring responsibility for follow-up activity.

Taking these elements into account, the aim of this article is to describe and discuss how the search conference can be used as a participative planning method for evidence-based health promotion actions in local communities. Experiences with the method are drawn from three Norwegian municipalities as part of an innovation project called Innovation in public sector - from knowledge to action - from action to knowledge. ${ }^{22}$ The study was approved by the Norwegian Social Science Data Service. This article concentrates on how the municipalities use strong evidence to identify, develop, and anchor health promotion actions by involving citizens, rather than by implementing actions themselves.

\section{Design and methods}

\section{The search conference}

The search conference as a method was originally developed in Australia by Fred and Merrelyn Emery and colleagues. ${ }^{17-19}$ The method enables participants to create a plan for the most desirable future of their community or organisation. ${ }^{18}$ In line with the description of approaches that are important for accomplishing evidence-based health promotion, ${ }^{5,7}$ the search conference methodology involves participation that is aimed at increasing responsibility within the local community. ${ }^{20}$ It is a practical tool for strategic planning that enables a large group to create a plan that they themselves will implement. ${ }^{19}$

Emery and Purser ${ }^{19}$ describe the search conference as a method for learning and planning, arguing that when people are provided with an opportunity for learning and planning, in the right environment, they will mobilise themselves to act purposefully in the interest of the whole. It is a practical tool for strategic planning. The method challenges the traditional viewpoint that planning is something reserved for the elite, and not for the masses. On the contrary, it is a method in which participants act democratically instead of bureaucratically by discussing and working with others, taking the situation of their own environment into consideration, and planning and implementing new ideas in the community.

In addition to the core principles, the method is based on a set of assumptions about people, namely that: $i$ ) they are purposeful creatures with the capacity to select and produce desirable outcomes, ii) they will accept responsibility for a task that is meaningful for them, and iii) people can function in the ideal-seeking mood under appropriate conditions. ${ }^{19}$

There are three main phases in a search conference: i) planning and design; ii) the search conference itself; and iii) implementation and diffusion.

\section{Planning and design}

There is no single style of search conference that can be applied to all situations. Instead, Emery and Purser ${ }^{19}$ state that it is important to 
follow the purpose of the conference and the theoretical principles. The planning of a conference is said to be the key to success, ${ }^{19}$ deciding if this method is the right one to use and, if so, defining the purpose of the conference and selecting who to invite as participants.

After the purpose of the conference has been determined, criteria for participation have to be decided. Participants are carefully selected. Most often they are persons who can bring new perspectives to the table, or who are known to be actively concerned with the purpose of the conference, or who can represent different kinds of knowledge, experience, opinions or responsibility that are needed for the topic. The process of selecting participants can take time and the planners are advised to ask for as many suggestions of relevant persons as possible in order to ensure the involvement of significant stakeholders. ${ }^{19}$

According to Emery, ${ }^{17}$ the search conference should have 15-35 participants. The planning stage also involves discussions about how much time to spend on the conference itself. Emery ${ }^{17}$ states that it should be rarely necessary to extend a search beyond two or three days and nights. In later descriptions, a length of $2 \frac{1}{2}$ days is recommended. ${ }^{19}$

The search conference itself consists of three phases, which resemble a funnel. ${ }^{19}$ In the first, scanning the environment, the participants learn about changes and trends in their external environment. This is followed by the second phase, exploration of the individual components of the system, which can be, for example, a workplace or a municipality, depending on the topic of the conference. As in the future search conference, the participants are looking into the system's past and present to develop goals for creating a desirable future. The third phase involves discussions and decisions about the future, focusing on identifying potential constraints, how to develop solid action plans, strategies used for implementation, assigning responsibility, and the potential impact on other relevant stakeholders.

During this portion, there are no experts or keynote speakers, games or icebreakers, training sessions, or other methods to help the process. In line with the basic assumptions about people, an open process is emphasised to help generate ideas from everyone regardless of their position or status. Flip-chart paper is used to visually display all ideas.

Conference work takes place in small groups or plenary sessions. The role of the leaders is to be experts on the design and management of the conference, which means running the meeting rather than being directly involved in data analysis.

The method presented here is inspired by the work of Emery and Purser, ${ }^{19}$ conducted at the Centre for Rural Research in Norway, where the first author learned and experienced the search conference method, and also by the work of Brokhaug, ${ }^{20}$ who has used the method in several local Norwegian communities.

The process of the search conference in Norway has been illustrated in a diagram (Figure 1) that includes the main elements of the conference in the funnel shape described by Emery and Purser. ${ }^{19}$ The original source of the figure used in this article is unknown, but to the best of our knowledge it was developed at the Centre for Rural Research and Institutt for industriell miljøforskning in Trondheim, Norway. The figure consists of elements described by Emery and Purser, ${ }^{19}$ while the text includes various other concepts. These concepts describe what was actually done in the preparation and implementation stages of the conference described below.

The following section will describe and discuss how the search conference, as presented above, was carried out in three Norwegian municipalities.

\section{The search conferences in municipalities $\mathrm{A}, \mathrm{B}$, and $\mathrm{C}$}

\section{Municipality description}

The search conferences presented in this study were conducted at the end of 2013 through the beginning of 2014. The municipalities differed in size, number of inhabitants, categorisation as to urban or rural, types of work places, population growth, educational level, income level and life expectancy (Table 1).

\section{Preparation and planning}

These three conferences were part of a health promotion project, ${ }^{22}$ with the aim of developing methods and models for health promotion actions as well as describing scientific evidence of these processes in each municipality. The search conference method was used to develop health promotion action plans, building on what politicians were expecting and based on scientific evidence, local resources, the participation of stakeholders, and intersectoral collaboration. The conferences were planned on the basis of each municipality's unique situation by a cross-sectorial project group representing research institutions as well as local and regional governments. During the preparation and planning process, representatives from the local and regional governments had the responsibility of stating the purpose of each conference, while the researchers were responsible for the structure of the search conference. Each municipality had a local project group with a project leader.

As these conferences were all connected to one larger project, their primary purpose was identical: to develop ideas about health promotion actions and action plans in line with evidence based on the challenges present in each municipality.

Table 1. Municipality description.

\begin{tabular}{|c|c|c|c|c|c|c|}
\hline Municipality & Inhabitants & $\begin{array}{l}\text { Rural: } \\
\text { urban last } \\
\text { year, \% }\end{array}$ & $\begin{array}{l}\text { Population } \\
\text { growth }\end{array}$ & Education & $\begin{array}{l}\text { Low income } \\
\text { residents }\end{array}$ & $\begin{array}{l}\text { Life } \\
\text { expectancy }\end{array}$ \\
\hline A & 13,500 & Suburb: rural & 0.95 & $\begin{array}{l}\text { Better than } \\
\text { the country as a whole }\end{array}$ & $\begin{array}{l}\text { Better than in the } \\
\text { country as a whole }\end{array}$ & $\begin{array}{l}\text { Better than } \\
\text { the country as a whole }\end{array}$ \\
\hline B & 21,650 & Urban: inland, farming & 0.44 & $\begin{array}{l}\text { Not significantly } \\
\text { different from } \\
\text { the country as a whole }\end{array}$ & $\begin{array}{l}\text { Not significantly } \\
\text { different from } \\
\text { the country as } \\
\text { a whole }\end{array}$ & $\begin{array}{l}78.6 \text { years for } \\
\text { men and } 82.4 \text { years } \\
\text { for women. } \\
\text { Not significantly } \\
\text { different from } \\
\text { the country as a whole }\end{array}$ \\
\hline C & 4360 & $\begin{array}{l}\text { Densely populated area: } \\
\text { coast, fish and fish-farming } \\
\text { industry }\end{array}$ & 0.97 & $\begin{array}{l}\text { Significantly lower than } \\
\text { the country as a whole }\end{array}$ & $\begin{array}{l}\text { Significantly better } \\
\text { than the country } \\
\text { as a whole }\end{array}$ & $\begin{array}{l}78.6 \text { years for men and } \\
82.9 \text { years for women. } \\
\text { Not significantly } \\
\text { different from } \\
\text { the country as a whole }\end{array}$ \\
\hline
\end{tabular}


During the planning process, the project group worked closely with leaders of public health initiatives in each municipality, identifying and combining a broad spectrum of knowledge from municipality data, health register data, and experience- and user-based knowledge, acknowledging that a combination of scientific evidence and values, resources, and contextual factors should be considered in the decisionmaking processes. These discussions, along with a review of the relevant knowledge, ended with an agreement on the choice of central topic for the conferences in each municipality (Table 2).

Brokhaug ${ }^{20}$ emphasises the importance of local mobilisation, defined as the process of finding those people who will be important to the future of the local community. Finding and deciding who to invite to the conference requires knowledge about the citizens and their special resources. Selection criteria for individuals included people who could bring new perspectives and represent different kinds of knowledge, experience, opinions or responsibility on the topic of interest. The participation of various leaders or decision-makers in the community was crucial to secure the implementation of any planned actions. As cross-sectorial cooperation is an important principle in health promotion action, it was also of special concern in this case.

There will always be questions regarding the selection of individuals, as the decision of who fits the selection criteria becomes a legitimate issue. Emery and Purser ${ }^{19}$ advise planners to discuss these questions with a number of people to make sure individuals are carefully and correctly selected. If, in the end, there are too many potential individuals to invite, drawing lots can be a way to settle the matter. The municipalities represented in this project were relatively small, meaning those individuals and their colleagues from the local project group were familiar with those individuals who were central to the municipality. At the same time, the principles of involvement in Norwegian municipalities point to the inclusion of representatives from all political parties, relevant municipal agencies, various businesses and nongovernmental organisations. To minimise the risk of non-inclusion of important individuals, it was important to dedicate adequate time to this part of the planning process and actively seek out these individuals. The participants selected for these conferences included public health leaders (heads of health and social sectors in the municipality), leaders with organisational and policy responsibilities and/or experience (the head of administration in the municipality and leaders/members of different political committees in the municipality, respectively), non-governmental organisations (NGOs) (representing the Red Cross, Save the Children Fund, youth organisations, religious congregations, and sports organisations), and individuals with special interest and competence in each of the conference subjects. The NGOs were represented by 7 participants in municipality B, 1 participant in municipality $\mathrm{C}$, and none in municipality $\mathrm{A}$. The participants as a whole represented an intersectoral group. Invitation letters were sent to selected individuals, containing information about the purpose of the conference and the work process. Not all invited individuals ended up attending the conference.

Although Emery and Purser ${ }^{19}$ describe search conferences as lasting two-and-a-half days, the conferences described here began at lunch on day one and ended by lunch on day two. The participants went home in the evening. Due to this time frame being shorter than normally advised, some parts of the conference were eliminated, time use was shortened, and other elements were added to reach the aim of the conference in the allotted time. This time scheduling left the leaders of the conference ample time in the evening to prepare for the next day.

The number of participants generally followed the recommendations from the literature: ${ }^{19}$ however, the smallest municipality contributed only 15 participants. Although the invitation letter emphasised the importance of participation for the duration of the whole conference in order to achieve continuity and ownership of decisions, in all municipalities there were participants who left for either brief or even considerable amounts of time.

Emery ${ }^{18}$ emphasises that the leaders of the search conference do not

Table 2. Participants and topics for the conference.

\begin{tabular}{|c|c|c|c|}
\hline Municipality & N. participants & Topics for the conference/challenges to be worked on & Project planned \\
\hline A & 30 & $\begin{array}{l}\text { Health-promoting communities with a focus on residential } \\
\text { environment and industrial and commercial development }\end{array}$ & A path along the coastline \\
\hline B & 30 & Perceived or real outsiderness & Public health in city center \\
\hline $\mathrm{C}$ & 15 & $\begin{array}{l}\text { Health promotion. Growth conditions for children and } \\
\text { adolescents in the municipality }\end{array}$ & Wellbeing and growth \\
\hline
\end{tabular}

\section{Introduction}

- What do we want to achieve?

- What knowledge do we have about the topic?

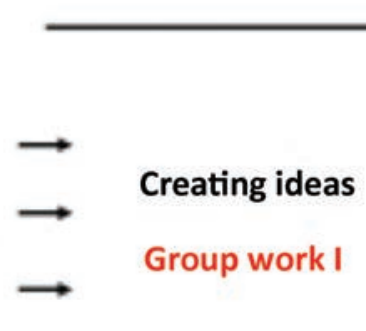

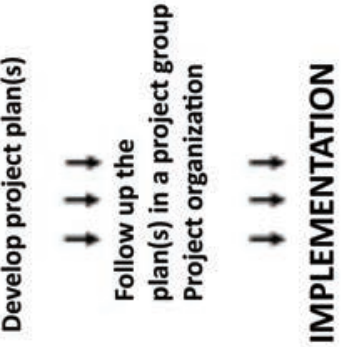

Group work II

Figure 1. The search conference. 
have to be experts on the topic of interest, but they must have sufficient confidence in the search conference method. The leaders of these conferences played double roles, as they were also researchers following the project. They were not experts on the challenges faced by each municipality, and as such did not involve themselves in topics other than those related to the conference process.

\section{The conference}

The conferences themselves started with presentations by the leaders and all participants, covering both the aim of each particular conference and the search conference as a method. Instead of involving the participants in scanning the environments, ${ }^{19}$ two to three short presentations, including strong evidence, were used to educate participants on the issues. Evidence from research, professional experience, local business activities, and/or user organisations was presented in order to lay a foundation for the development of action plans. Replacing one group work session with presentations given to all participants was preferable in order to complete the conference in the allotted time. There were three total presenters in each municipality, and all were given 15-20 minutes each. Presentations represented knowledge from professional work and personal experiences. The topics included Health promotion in a life course perspective-possibilities and challenges; Young people: bullying and mental health; and Health-promoting environments.

The question of who should be invited to make presentations became part of the planning process. According to research by Emery and Purser, ${ }^{19}$ experts or individuals other than participants in the conference should not be invited as presenters. Instead, this knowledge should be represented by someone in the conference group. The search conferences presented here made a different decision by inviting one individual from municipality $A$ and one from $B$ who were not participating in their respective conferences. Their presentations were considered important for the participants in their work on the conference topic.

\section{Create ideas}

After presentations, the next step is to Create Ideas, which Emery and Purser ${ }^{19}$ call focusing on the system. In order to develop ideas relevant to the conference topic, small groups were asked to discuss the following question: With your experiences, knowledge, and what you have heard today, what health promotion projects are of current interest in your municipality? The purpose of the question was to make the participants generate as many ideas as possible that were relevant to actions that promote health, by building on the presented evidence.

To stimulate open and accepting communication during the group discussions, eight minutes were spent allowing the participants to experiment with various ways of responding to suggestions in a group exercise. Although this focus on how to communicate in order to create good ideas was met with laughter and a feeling of recognition in how communication can be difficult, this kind of exercise is not a part of the original search conference design. ${ }^{19}$ The reasons for this have to do with the assumptions and principles of the search conference: that people who want to participate and who accept its purpose will take responsibility and contribute in positive ways. Due to time constraints and also to emphasise the equality of all participants, a judgment was made to help the participants keep a positive focus on the involvement of all, emphasise the importance of communication, and assemble ideas from all participants by not judging but rather by building on ideas from each other. In line with Emery, ${ }^{17}$ who states that even the most far out improbable suggestions must be looked at, the rules for the group discussions were laid out as follows: to welcome all kinds of ideas and to build on the ideas of others.

The group discussion that followed lasted from one-and-a-half to two hours. In line with Emery and Purser, ${ }^{19}$ ideas were recorded on flip- chart paper to be shared and seen by all. At the end of the discussion period, several ideas were presented to the plenary group in five minutes or less, and then opened up for short questions. After this session, participants were free to leave.

\section{Categorising of ideas}

Throughout the day, the leaders had been involved in guiding processes during the conference but had not been involved in the topic discussions. After the participants had left, the leaders categorised the presented ideas. Categorising involved reading and interpreting the content of each idea presented on the flip-chart. The purpose of the categorising was to make a system from the ideas presented by grouping similar ideas into new themes. This process often has many solutions, but the important point is that all ideas fit into a theme and that the name of the theme fits all included ideas. Often ideas may be part of multiple themes. For example, one theme may include ten ideas for different projects while other themes may have just one or two. There is no limit to the number of themes. After categorising, each idea was written word for word on new flip-charts, using one for each theme. The following day all participants would find their ideas included in at least one place, indicating that all ideas were equally important at this stage.

This portion of the search conference deviated from the method described in the literature ${ }^{19}$ In line with a bottom-up perspective, and following the assumptions and principles of the search conference, this process of categorisation should have been left to the participants. Due to the time constraints, this was not done in the presented conferences. Instead, the leaders handled the categorisation and left the results for the participants to evaluate, modify, or transform the next day. This means the participants had to agree with how their ideas were categorised and agree on the name of the theme. They could choose to move an idea from one theme to another or to change the name of the theme. Participants were supposed to feel confident in how their ideas had been treated before moving on to the next step.

\section{Choosing a project idea}

The next step was to decide on which ideas participants were interested in developing into a project plan. Individuals were encouraged to work with an idea they believed was of special importance and, if possible, combine ideas into one project plan. This could be a time-consuming part of the process that also involved deciding on whom to work with. After everyone had selected an idea to work on, the process ended with new groups of three to eight people. During this process, a few of the ideas presented the day before were selected. This meant that ideas of vital importance to the community might be left out, while others of less importance could be selected, resulting in disagreements and discussions. Therefore, it was crucial to allot enough time for this part of the process. Arguments, disagreements, and the evaluation of selected ideas was presented and considered by the plenary group.

\section{Developing a project plan}

After agreements had been made on which ideas to develop further, new groups were formed. To help the groups get started in developing a plan, they were asked to come up with a group name and present their resources to each other. There are different creative ways of doing this and, again, this was not in line with the suggestions from Emery and Purser. ${ }^{19}$ By giving people different tasks that stimulate creativity, the individual can use personal resources that they may not have used when discussing the subject of the conference. Throughout this creative process, members are also provided with the opportunity to become more familiar with each other in a short period of time.

The task of the group work was now to develop a project plan. To help structure the plan, groups were given central cues to cover: the title of the project; a description of the idea; how to realise it, aim, and frames; 
target group(s); time frame; organising; barriers; and criteria of success. Depending on the amount of time available, the groups outlined one project in as much detail as possible.

\section{Presentation of project plans}

Each group was given ten minutes to present their plan to the rest of the conference participants. There was also some time for questions and short discussions about each plan. As a result, there was little time left over for the discussion of the decision-making process. Each conference resulted in two to three ideas focused on health promotion projects for each municipality.

\section{Follow-up}

The last portion of the search conference is called Implementation and Diffusion, ${ }^{19}$ which is the work that follows the face-to-face meetings at the conference and which can continue for years depending on the character of the project, financial status, and other available resources for implementation.

Before leaving the conference, the participants were informed about who would be responsible for the follow-up process, project organisation, and timetable. In these municipalities, the local project leader together with leaders from the project Innovation in the public sector from knowledge to action - from action to knowledge were responsible for following up on the presented projects.

\section{Evaluation}

At the end of the conference the participants were asked to take a few minutes to evaluate the conference, noting their immediate reflections on three questions: i) what have been the benefits of working in this way? ii) What have been the drawbacks of working in this way? iii) Who else should have been invited? Their written reflections were systematised for each municipality and then evaluated across the board. Some examples of the benefits listed were: The sharing of knowledge, Groups give creativity, Learning, Openness-take care of ideas, Structured process - a good working method, Group discussions were good, A systematic approach, To participate in a process led by someone from outside, To learn about the competences of others, Ideas that I have not thought about myself, New perspective. The listed drawbacks included: Ideas can be lost, or be less sharp due to compromises, Too little time for discussions after the presentations from the groups, Time - short on time, High intensity, Some perspectives from some of the citizens are not represented, Some of the persons invited did not show up, Unclear what is going to happen now. To complete the intersectoral, there were also suggestions about citizens who ought to have participated, such as: Individuals from the young people's board to get their opinions, More politicians, Maybe more representatives from stakeholders as theatre, chorus, brass band, Pupil council, More people from the private sector.

After the conference, the local project leader in each municipality had a working group of individuals who had attended the search conference. Together this group continued to discuss project plans with other representatives, groups, and individuals in the municipality before deciding which plan would be developed further for political decision-making. Furthermore, each local project group decided whom to involve in these discussions throughout the process. These included, among other groups, children at a nursery school, children in lower secondary school, elderly persons living at home, groups of homeless people, and immigrants. Intersectoral representation was important in order to ensure that as many stakeholders as possible were considered before beginning implementation of a plan.

At this stage, each municipality is now working on implementing action plans based on work conducted at the research conference.

\section{Discussion}

Health promotion initiatives in Norwegian municipalities are expected to be evidence-based and integrated into the local democracy. One of the reasons for this is that locally democratic societies that are structured to support involvement and participation also have increased social trust and social capital. ${ }^{2}$ The question in this article is whether the search conference, as a participative planning method, meets these expectations when planning community health promotion actions.

The search conference method emphasises the importance of the planning process, focusing on present challenges of high importance for the community. Other central elements of the search conference include finding participants who can contribute, working knowledgebased, valuing the available resources of all participants and their decisions, and ensuring responsibility for follow-up activity.

In order to make evidence-based decisions, those planning the conference must investigate a broad spectrum of knowledge from the community relevant to the topic of interest. Some communities may realise that they lack the relevant scientific knowledge or data for their community and must therefore consider this factor when deciding how and what to present.

Although there had been broad discussions regarding whom to invite to participate in the conferences, a post-conference evaluation by the participants illustrated that several stakeholders were missing from the process, such as business professionals, non-governmental organisations, and pupils from lower secondary school. Even if the aim was to choose a representative sample of the entire community, we learned that even broader discussions, as described by Emery and Purser, ${ }^{19}$ would have been beneficial, especially when it came to NGOs and different age groups. In particular, as the theme in one of the municipalities was related to young people, the youth viewpoint should have been represented. Even if representation of citizens was emphasised, the local and regional governments could decide on who to invite. To ensure a broader spectre of citizens even more work should be done in this matter. At the same time, all the participants of the conference lived in these municipalities. They were not strangers. They had knowledge from their everyday life of the challenges they worked on, and developed plans about the everyday life of their community.

Also, a special effort in getting central leaders and politicians to participate would have benefitted the process. In municipality $\mathrm{C}$, key individuals, such as the chief municipal executive, did not participate, which was later regarded as negative. The participation of a leader in a small community - one who is responsible for following through on the planned actions - can be crucial in order to support the implementation processes later. For leaders, understanding the rationale for prioritising particular actions can simplify their responsibilities during the follow-up process.

The way in which the presented search conferences were planned can be called a top-down approach, meaning, in this case, that participants were not free to influence the topics of focus, the list of persons invited, or the timetable. On the other hand, a bottom-up approach may not guarantee that a greater number of key individuals are invited, and can result in the participants experiencing ownership of results in a very different manner. At the same time, a bottom-up approach can make intersectoral collaboration difficult, as knowledge about particular individuals may reside with the administration. Decisions in the planning process will likely depend on several elements, including the size of the community, the purpose of the conference, the topic of focus, and how familiar the planning group is with its citizens. To achieve comprehensive involvement and ensure both intersectoral collaboration and a broad spectrum of stakeholders, the individuals involved in planning should be familiar with various parts of the com- 
munity. The aim of health promotion actions is to promote public health and well-being ${ }^{1}$ and to build decisions based on strong evidence. ${ }^{5-7}$ The search conference in this project planned to develop new evidence-based actions. Although presentations for the participants were planned to underline the importance of evidence-based decisions, ideas and prioritised actions were made by the participants and were out of the hands of those planning the conference, which is a standard consequence of a bottom-up approach. As seen in other projects, ${ }^{9-11}$ a combination of the bottom-up and top-down approaches is central to developing sustainable initiatives in communities. At the same time, this method could be in conflict with building interventions based on strong evidence. Emery and Purser ${ }^{19}$ would argue that people have the capacity to select and produce desirable outcomes and accept responsibility for tasks that are meaningful to them. Based on these assumptions, it is important during the planning process to organise the conference so that it provides participants with the opportunity to make decisions that are meaningful for them and to contribute to a positive process. Decisions regarding whom to invite for presentations and participation are crucial to the results.

The participants noted that the time frame of the conferences was limited. This time frame was also shorter than what is recommended in the literature. ${ }^{19}$ Planning for a shorter time frame can make it easier to get people involved. Often people are busy and will encounter difficulties getting off of work, or may have economic limits as result of the fact that participation in the conference is voluntary and without payment. These issues are important to discuss when inviting participants. Budgeting to cover forfeiture of salary for NGOs could be necessary to ensure participation of a broad spectrum of citizen groups. However, although having a limited time frame can make it easier for people to participate, it can also have negative consequences, as when the groups were discussing project plans. As these plans can have major consequences for the municipality, more time for discussion and reflection could be helpful to ensure the importance of each idea and see that the plan for action is well understood. The limited timeframe could be viewed as the most significant drawback of the process and could be causing difficulties, pressing participants to make decisions before they are able to reach an agreement. During such a discussion, the participants should have an opportunity to evaluate each project plan and outline priorities.

Setting aside more time for discussions, or voting on ideas as done in the consultative conference approach, ${ }^{15}$ may provide a solution. Voting, however, would not be in line with the assumptions of Emery and Purser, ${ }^{19}$ even if it is a democratic way of making decisions. Therefore, allowing more time for conferences should be considered for several reasons.

Although citizen involvement is crucial in health promotion, and bottom-up approaches can be seen as an important strategy for empowerment and participation, Fosse ${ }^{9}$ found that collaboration with local community administration was the most successful. During the search conference, from the first working group until the final presentation of project plans on day two, a bottom-up strategy was emphasised. The way this phase was organised and led underscores the value of the contributions and involvement of all participants in making decisions for the future action development of their community. According to Arnstein, ${ }^{8}$ these phases can be placed above the middle of the participation ladder, at the citizen control step, as distinct from the planning process of the conference where there is no participation.

This means that the search conference, as presented here, represents a mixture of bottom-up and top-down approaches. It differs in many ways from the original concept, ${ }^{18}$ including how to decide who to invite, the presentation of evidence, the timetable, and the categorisation of ideas into themes. This is in line with the supersetting approach presented by Bloch and colleagues ${ }^{11}$ and by Mittelmark and colleagues, ${ }^{10}$ which emphasises the complexity of health promotion actions that make both approaches necessary.

Similar to other dialogue conferences, ${ }^{12-15}$ the search conference ${ }^{19}$ is a structured method of planning community health promotion actions. Elements such as scientific evidence, leadership, local resources, participation with open dialogue and debate, and intersectoral collaboration are central. The voice of each participant should be heard and the responsible part should be identified to all. In this manner, the search conference method meets political expectations for health promotion initiatives. There is also the question of whether the search conference might be seen as community innovation. By working in a new way, involving different knowledge bases and participants, results might lead to unexpected, innovative consequences. In the participants' comments evaluating the conference, the most significance was given to the creative process that led to new and unexpected ideas in combination with new knowledge from other participants. These are also positive elements for follow-up in each municipality and could influence other processes in the future.

\section{Conclusions}

The search conference method as presented in this article can be a useful strategy for involving a community in the planning of health promotion actions. The method represents a mixed strategy using both bottom-up and top-down approaches. This might challenge the evidence-based health promotion approach; however, the methodology gives the participants opportunities to use their knowledge and experiences. Taking these elements into consideration, the most important factor when planning a search conference is to emphasise what knowledge to present. By including individuals who can present important evidence-, experience-, and user-based knowledge, as well as take responsibility for follow-up issues, the conference method might facilitate the development of good and sustainable health promotion actions. The possible challenge related to using evidence-based knowledge during the search conference process should, however, be taken into account and further developed. Questions of who to invite for participation and decisions on the timetable also have to be considered. There should be enough time, and the right participants should be invited to work on the topic decided.

Correspondence: Eva Magnus, Faculty of Health and Social Science, Department of Health Science, Norwegian University of Science and Technology, Tungasletta 2, N-7004 Trondheim, Norway.

Tel.: $+47.92247215 ;+47.73559223$.

E-mail: eva.magnus@ntnu.no

Key words: Search conference; health promotion; evidence-based; partecipation; bottom-up approach; top-down approach.

Acknowledgements: the authors will thank the three municipalities, for participating

Contributions: the authors contributed equally.

Conflict of interests: the authors declare no potential conflict of interest.

Funding: this work was supported by Regional Research Funds in Norway (project no. ES 469747/209033).

Received for publication: 3 September 2015.

Accepted for publication: 2 March 2016.

(C) Copyright E. Magnus et al., 2016

Licensee PAGEPress, Italy

Journal of Public Health Research 2016;5:621

doi:10.4081/jphr.2016.621

This work is licensed under a Creative Commons Attribution NonCommercial 4.0 License (CC BY-NC 4.0). 


\section{References}

1. Public Health Act of 2012. Oslo: Ministry of Health and Care Services; 2012.

2. Ministry of Health and Care Services. White paper no. 34. Public Health Report. Good health-a common responsibility. Oslo: 20122013.

3. World Health Organization. Action for Public Health. Sundsvall Statement on Supportive Environments for Health. Sundsvall; 1992.

4. World Health Organization. The Helsinki Statement on Health in All Policies. Proceedings of the $8^{\text {th }}$ Global Conference on Health Promotion. 2013 Jun 10-14; Helsinki, Finland.

5. Brownson RC, Fielding JE, Maylahn CM. Evidence-based public health: a fundamental concept for public health practice. Ann Rev Public Health 2009;30:175-201.

6. Raphael D. The question of evidence in health promotion. Health Promot Int 2000;15:355-67.

7. Brownson RC, Gurney JG, Land GH. Evidence-based decision making in public health. J Public Health Manag Pract 1999;5:86-97.

8. Arnstein S. A ladder of citizen participation. AIP J 1969;35:216-24.

9. Fosse E. National objectives-local practice: implementation of health promotion policies. In: Wold B and Samdal 0, eds. An ecological perspective on health promotion systems, settings and social processes. Bergen: University of Bergen; 2012. pp 34-9.

10. Mittelmark MB, Wold B, Samdal 0. The ecology of health promotion. In: Wold B and Samdal 0, eds. An ecological perspective on health promotion systems, settings and social processes. Bergen: University of Bergen; 2012. pp 85-9.

11. Bloch P, Toft U, Reinbach HC, et al. Revitalizing the setting approach: supersettings for sustainable impact in community health promotion. IJBNPA 2014;11:118.

12. McDonald D, Bammer G, Deane P. Research integration using dia- logue methods. Canberra: The Australian National University; 2009.

13. Baheiraei A, Mirghafourvand M, Mohammodi E, et al. Determining appropriate strategies for improving women's health promoting behaviours: Using the nominal group technique. EMHJ 2013;19:409-16.

14. Twible RL. Consumer participation in planning health promotion programmes: a case study using the Nominal Group Technique. Aust Occup Ther J 1992;39:13-8.

15. Sartore G, Hoolahan B, Tonna A, et al. Wisdom from the drought: recommendations from a consultative conference. Aust J Rural Health 2005;13:315-20.

16. Apel H. The Future Workshop. Available from: http://www.diebonn.de/esprid/dokumente/doc-2004/apel04_02.pdf

17. Emery M. Searching: For new directions, in new ways, for new times. Canberra: Centre for Continuing Education, Australian National University; 1982.

18. Rehm R and Celuba N. The search conference method for participative planning. (Adapted from the article "The Search Conference: State of the Art," by Merrelyn Emery) 1995.

19. Emery M, Purser RE. The search conference. A powerful method for planning organizational change and community action. San Francisco: Jossey-Bass Inc; 1996.

20. Brokhaug IK. Handlingsrettet lokalsamfunnsforskning med søkekonferanse som basismetode. Trondheim: IFIM Rapport; 1983.

21. Future Search Network (Internet). Philadelphia: Future Search Network 2001-2015, Sandra Janoff and Marvin Weisbord, CoDirectors (cited 2015 December 17). Available from: http://www.futuresearch.net.

22. Lillefjell M, Knudtsen MS, Wist G, et al. From knowledge to action in public health management: experiences from a Norwegian context. Scand J Public Health 2013;41:771-7. 